\title{
Influence of E-smoking liquids on human periodontal ligament fibroblasts
}

Ines Willershausen ${ }^{1}$, Thomas Wolf ${ }^{1}$, Veronika Weyer ${ }^{2}$, Robert Sader ${ }^{3}$, Shahram Ghanaati ${ }^{3,4}$ and Brita Willershausen ${ }^{1 *}$

\begin{abstract}
Introduction: Over the last years, electronic cigarettes (ECs) have become more popular, particularly in individuals who want to give up smoking tobacco. The aim of the present study was to assess the influence of the different e-smoking liquids on the viability and proliferation of human periodontal ligament fibroblasts.

Method and materials: For this study six test solutions with components from ECs were selected: lime-, hazelnut- and menthol-flavored liquids, nicotine, propylene glycol, and PBS as control group. The fibroblasts were incubated up to $96 \mathrm{~h}$ with the different liquids, and cell viability was measured by using the PrestoBlue ${ }^{\oplus}$ reagent, the ATP detection and the migration assay. Fluorescence staining was carried out to visualize cell growth and morphology. Data were statistically analyzed by two-tailed one-way ANOVA.
\end{abstract}

Results: The cell viability assay showed that the proliferation rates of the cells incubated with nicotine or the various flavored liquids of the e-cigarettes were reduced in comparison to the controls, though not all reductions were statistically significant. After an incubation of $96 \mathrm{~h}$ with the menthol-flavored liquid the fibroblasts were statistically significant reduced $(p<0.001)$. Similar results were found for the detection of ATP in fibroblasts; the incubation with menthol-flavored liquids $(p<0.001)$ led to a statistically significant reduction. The cell visualization tests confirmed these findings.

Conclusion: Within its limits, the present in vitro study demonstrated that menthol additives of e-smoking have a harmful effect on human periodontal ligament fibroblasts. This might indicate that menthol additives should be avoided for e-cigarettes.

Keywords: Cell proliferation, Electronic cigarettes, Fibroblasts, In vitro, Menthol, Nicotine

\section{Introduction}

The electronic nicotine-delivery device (electronic cigarettes, ECs) was developed and patented in 2003 by the Ruyan Group (Holdings) Limited in Beijing, China. After their launch on the market in Europe and the United States of America in 2006, e-cigarettes made headlines across the world [1]. Praised as an alternative to conventional cigarettes, e-cigarettes are intended for those who want to reduce or quit smoking. They can be used indoors when restrictions on conventional smoking are present, and have been marketed as environmentally friendly. The e-cigarette is an electronic nicotine delivery device that mimics the outward appearance of a conventional cigarette and has

\footnotetext{
* Correspondence: willersh@uni-mainz.de

'Department for Operative Dentistry, University Medical Center of the Johannes Gutenberg University Mainz, Augustusplatz 2, 55131 Mainz, Germany

Full list of author information is available at the end of the article
}

been recently introduced to the market worldwide [2]. While many different models are commercially available, all e-cigarettes consist of little more than three basic components: a battery-part, a heating element and a liquid-containing cartridge. The cartridge can be filled with different e-liquid solutions. These liquids are vaporized by the heating element, and the cigarette is 'consumed' by inhaling the liquids' aerosol mist, thus simulating the act of real tobacco smoking. The e-liquid is a simple solution with usually three main components. They contain diluents added to dilute the mixture and to vaporize upon heating; the most commonly used diluents are propylene glycol and vegetable or aqueous glycerin, usually as a mixture of $80 \%$ propylene glycol and $20 \%$ glycerin. In addition, flavors are often added to improve the taste of the e-liquid. Nicotine is often added to the propylene glycol in concentrations up to $70 \mathrm{mg} / \mathrm{ml}$. Propylene 
glycol, a colorless and odorless food additive, is a safe, commonly used chemical without any known harmful effects on human health. Nicotine, in contrast, is considered very harmful to both general and dental health. Tobacco smoke induces changes in cell structure and function by altering cell signaling pathways, which is predominantly harmful to bronchial and oral epithelial cells [3-5]. Adverse consequences on human health have been shown even for low cigarette consumption [6]. Cigarette smoke contains approximately 4800 chemicals, over 60 of which are known to have adverse effects on human tissues and cells, e.g. a high genotoxicity leading to various forms of DNA damage [7]. Tobacco smoking is responsible for $85 \%$ of lung carcinomas. According to WHO reports, cancer of the oral cavity is the eleventh most common cancer worldwide [8], while in South Central Asia it is the forth most common cancer [9]. Besides being harmful to overall health, the connection between smoking tobacco and developing periodontal disease is well documented in the literature. Studies have shown that smoking tobacco contributes to the progression of periodontal disease and adversely affects patients' response to non-surgical or surgical treatment [10-16]. Higher failure rates and increased complications after dental implant placement have also been documented in smokers [17]. Likewise, smoking is a predisposing factor to acute necrotizing ulcerative gingivitis [18]. Exposure to cigarette smoke is also considered an independent periodontal disease risk factor. Although e-cigarettes were initially introduced as a healthy alternative to conventional smoking; however, when they contain e-liquids supplemented with nicotine, health risks associated with conventional tobacco consumption might be expected. In a recent study it was shown that 10 to $81 \%$ of the nicotine from the cartridges was vaporized, corresponding to a range of 2.1 to $15.1 \mathrm{mg}$ nicotine [19]. According to a survey among users, ecigarettes are very popular, because they are supposed to assist with smoking cessation [20]. In in-vitro studies it has been shown that the vapors of the electronic cigarettes were significantly less cytotoxic than cigarette smoke extract [21].

The manufacturing process for e-liquids is not yet standardized, which carries the risk that cancer-inducing substances will enter the wide variety of e-liquids available on the market [22-25]. To date, tobacco-specific substances such as nitrosamines and aldehydes have already been detected in e-liquids. Since no evidencebased studies on the effectiveness of e-cigarettes for smoking cessation presently exist, and since the potentially harmful health effects of e-cigarettes have also not been tested, the use of e-cigarettes to replace cigarette smoking can not be recommended.

The aim of the present in vitro study was to examine, whether e-cigarette liquids and their various flavor components have a damaging influence on the viability and proliferation of human periodontal ligament fibroblast.

\section{Material and methods \\ Cell culture}

Clonetics ${ }^{\oplus}$ HPdLF (Human Periodontal Ligament Fibroblasts) were purchased from Lonza (BioWhittaker, Kerviers, Belgium). The fibroblasts were cultured in Dulbecco's Modified Eagle Medium (Molecular Probes, Carlsbad, CA) containing $1 \%$ penicillin/streptomycin (Molecular Probes, Carlsbad, CA) and 10\% fetal bovine serum (PAA, Pasching, Austria) and incubated under standard cultivation conditions $\left(37^{\circ} \mathrm{C}, 5 \% \mathrm{CO}_{2}\right.$ and $95 \%$ air). Cells from the 4th to the 6th passage were used for the PrestoBlue Viability Assay, the ApoGlow BioAssay, cell visualization by means of fluorescence staining and the Migration Assay.

\section{Liquids for electronic cigarettes}

The tested e-smoking liquids (eSmokerShop, GmbH, Hannover, Germany) all contained in addition to various flavors the components nicotine (20-22 mg/ml) and, as additive, propylene glycol. Liquids with the flavors hazelnut (filbertone; trans-5-Methyl-2-hepten-4-one; $20 \mathrm{mg} / \mathrm{ml}$ nicotine) [26], lime (20 $\mathrm{mg} / \mathrm{ml}$ nicotine) [27,28] and menthol (5-methyl-2-propan-2-ylcyclohexan-1-ol; $22 \mathrm{mg} / \mathrm{ml}$ nicotine) as well as the test substances nicotine and propylene glycol (Sigma-Aldrich Chemie $\mathrm{GmbH}$, Steinsheim, Germany) were included in the investigation. Dose-response curves were established for nicotine and for the mentholflavored e-smoking liquid. From preliminary experiments with the menthol-flavored liquid a concentration of $10 \mu \mathrm{g} / \mathrm{ml}$ was determined as best suited for all tests described below. To allow for comparisons, all test liquids were therefore diluted with serum-free Dulbecco's Modified Eagle Medium (DMEM), resulting in a final nicotine concentration of $10 \mu \mathrm{g}$ nicotine per ml test liquid. There were in total six test groups: control group (PBS); propylene glycol; nicotine; three e-liquids, one with hazelnut flavor, one with lime flavor and one with menthol flavor. The following assays were employed to study the influence of the above mentioned test solutions on the vitality and proliferation of fibroblast cells.

\section{PrestoBlue Cell Viability Assay}

The PrestoBlue Cell proliferation assay (Molecular Probes, Carlsbad, CA) contains a growth indicator which becomes reduced by metabolically active cells to a fluorescent agent. To investigate the influence of the different liquids, the periodontal fibroblasts $(10,000$ cells $/ 200 \mu \mathrm{l} ; \mathrm{n}=6$ for each test) were placed into 96 multi well plates and were then incubated up to $96 \mathrm{~h}$ with the different liquids. Control cells were incubated only with the same volume of DMEM. 
After $0,1,3,6,24,72$ and $96 \mathrm{~h}$ of incubation with 5\% PrestoBlue, fluorescence was measured at a wavelength of $530 / 25 \mathrm{~nm}$ and $590 / 35 \mathrm{~nm}$ with a fluorescence reader (Synergy HT-Reader, BioTek, Winooski, VT). Logarithmic signals were converted to a linear scale and expressed as relative fluorescence units (RFU).

\section{ATP-Detection}

The ATP detection was performed with the ApoGlow Bioassay kit (Lonza, BioWhittaker, Kerviers, Belgium). For this assay 30,000 cells/well ( $n=6$ for each test) were grown to confluence for about $24 \mathrm{~h}$. The supernatants were removed and the cells were incubated for $24 \mathrm{~h}$ with the various test liquids. Then ATP was determined using the ApoGlow Bioassay kit. Luminescence was measured with a luminescence reader (Synergy HT-Reader, BioTek, Winooski, VT) and analyzed with Gen 5 (BioTek, Winooski, VT).

\section{Cell visualization}

Calcein-AM/ethidium homodimer II staining (LIVE/DEAD Viability/Cytotoxicity Kit; Molecular Probes, Carlsbad, CA) is a two-color fluorescence-based method for determining viability of cultured cells. Calcein is a fluorogenic esterase substrate that is hydrolyzed intracellularly to a green fluorescent product, which is an indicator of live cells. Ethidium homodimer enters cells with damaged membranes and intercalates with the DNA in the nucleus, emitting a red fluorescent signal. For cell visualization, the fibroblasts were incubated for $24 \mathrm{~h}$ with the different test solutions and after removal of the supernatant incubated with calcein-AM $(5 \mu \mathrm{l} / 10 \mathrm{ml}) /$ ethidium homodimer II $(10 \mu \mathrm{l} / 10 \mathrm{ml})$ at $37^{\circ} \mathrm{C}$ for $15 \mathrm{~min}$. The stained cells were then viewed in an inverted microscope at wave lengths of 450/520 nm (Axiovert 40C, Carl Zeiss, Jena, Germany) at a magnification of $\times 100$.

\section{Migration assay}

The migration assay (Greiner Bio-One GmbH, Frickenhausen, Germany) was performed with Boyden-Chambers (ThinCerts, Greiner Bio-One GmbH, Frickenhausen, Germany). For this investigation the fibroblasts $(10,000$ cells/well; $n=6$ for each test) were placed in Boyden-Chambers. The two compartments of the Boyden-Chamber are separated by a porous PET membrane. Then the test liquids $(600 \mu \mathrm{l}$ with a final concentration of $10 \mu \mathrm{g} / \mathrm{ml}$ nicotine) were added and incubated for $72 \mathrm{~h}$ at standard culture conditions. Migratory cells move through the pores. The fibroblasts were stained with calcein-AM (5 $\mu \mathrm{l}$ and $10 \mathrm{ml}$ PBS) for $15 \mathrm{~min}$ under culture condition. After incubation the cells were rinsed, placed in a new 24 multi-well chamber, and then incubated for $30 \mathrm{~min}$ with $300 \mu \mathrm{l}$ trypsin/EDTA. Afterwards, aliquots of $200 \mu \mathrm{l}$ were placed in a black 96 multi-well plate. Fluorescence was measured at a wavelength of 485/20 nm and 520/40 $\mathrm{nm}$ with a fluorescence reader (Synergy HTReader, BioTek, Winooski, VT) and analyzed with Gen 5 (BioTek, Winooski, VT). Logarithmic signals were converted to a linear scale and expressed as relative fluorescence units (RFU).

\section{Statistical analysis}

The statistical analyses of the data were performed using SPSS 20.0 (SPSS Inc., Chicago, Il.). For descriptive analyses, means and standard deviations were calculated for the normally distributed continuous outcome variables.

For confirmatory analyses two-tailed one-way ANOVA were performed to calculate overall p-values for the comparison of the different groups for each outcome variable.

Normality for outcomes was checked by visual inspection via quantile-quantile plots.

A power analysis for an ANOVA design was performed. With a sample size of $n=6$ per group a power between $75 \%$ and $100 \%$ is available for 7 outcomes.

The global significance level for all statistical test procedures was chosen as $\alpha=0.05$.

Post-hoc tests employing the Bonferroni correction for multiple testing were used for comparison of means of two groups.

\section{Results}

As can be seen in Figure 1, the PrestoBlue Cell viability assay showed that over an incubation time of $96 \mathrm{~h}$ the proliferation rates of the cells incubated with nicotine or the various flavored liquids of the e-cigarettes were reduced in comparison to that of the untreated control cells, though not all reductions were statistically significant. Starting at $24 \mathrm{~h}$, the highest reduction in the proliferation was observed for the treatment with menthol-flavored liquids, which was the only statistically significant reduction as compared to control cells.

After an incubation time of $48 \mathrm{~h}$ with the mentholflavored liquid the difference in comparison both to the control cells and the nicotine-treated cells was highly statistically significant $(\mathrm{p}<0.001)$. Hazelnut flavor or lime flavor only caused a slight not statistically significant reduction of the proliferation rates at $48 \mathrm{~h}$. After $96 \mathrm{~h}$ of incubation this strong growth-reducing effect of the menthol-flavored liquids persisted and was still statistically significant.

More pronounced differences were found using the ApoGlow Bioassay kit for the detection of ATP in fibroblasts after an incubation time of $24 \mathrm{~h}$ with the different test substances and flavored liquids (Figure 2). In comparison to the untreated cells, incubation with hazelnut-flavored $(\mathrm{p}<0.024)$, lime-flavored $(\mathrm{p}<0.009)$ or menthol-flavored liquids $(\mathrm{p}<0.001)$ led to a statistically significant reduction of the ATP detection. 


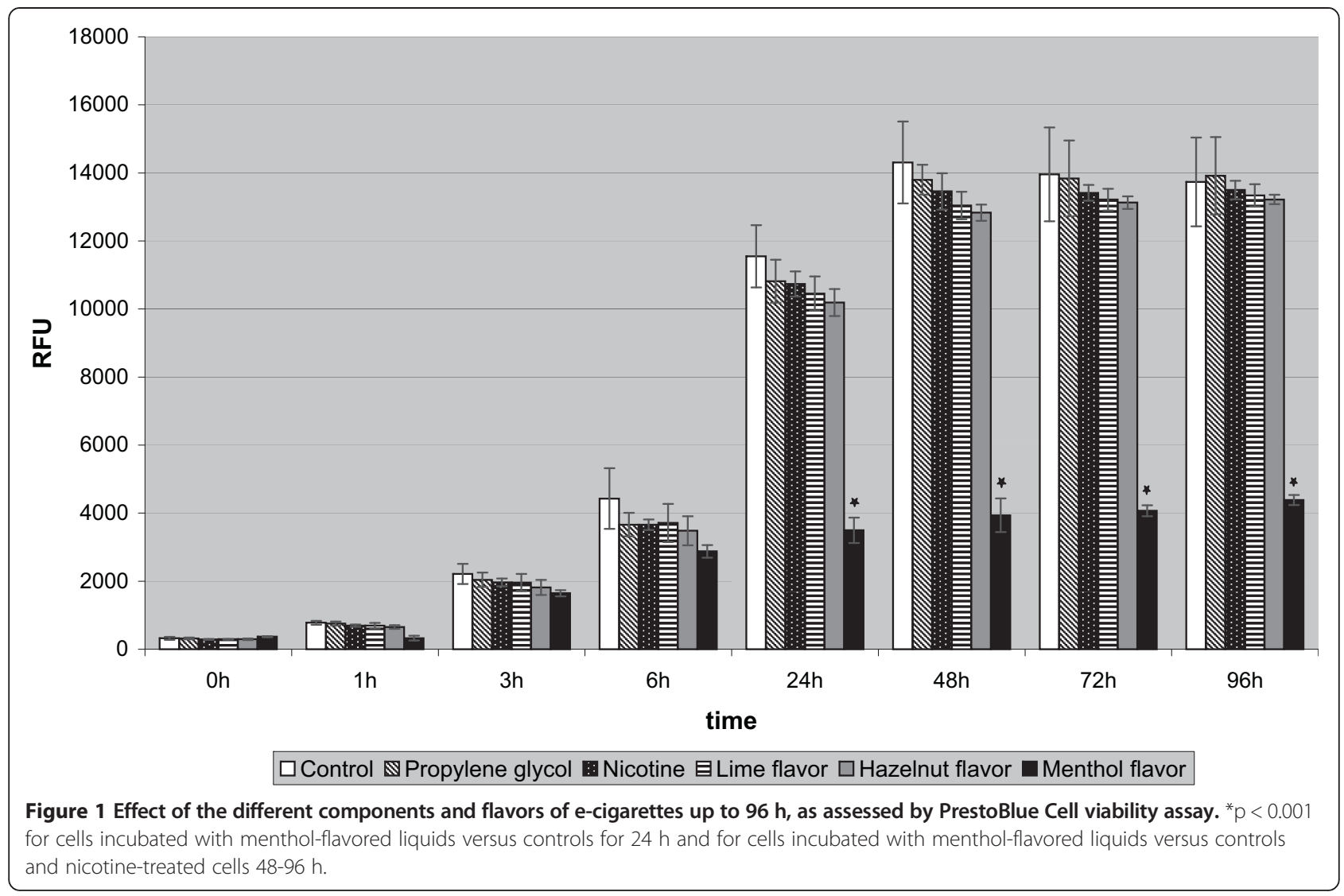

The findings from the ATP detection assay were confirmed by the visual analysis of the cells stained with calcein-AM/ethidium homodimer II. The untreated human periodontal ligament fibroblasts and those incubated for $24 \mathrm{~h}$ with propylene glycol showed good proliferation (Figures 3A,B). Those incubated with nicotine, hazelnutor lime-flavored liquids showed a slight (Figures 3C-E) growth reduction, while incubation with the menthol- flavored liquid produced a strong growth inhibition (Figures 3F).

The inhibitory effect of menthol flavor exposure on the fibroblast cells was especially noticeable in the migration assay (Figure 4). Only the menthol-flavored liquid caused a highly statistically significant reduction $(\mathrm{p}<0.001)$ of cell migration after $72 \mathrm{~h}$ in comparison to the control cells as well as to the cells treated with nicotine.

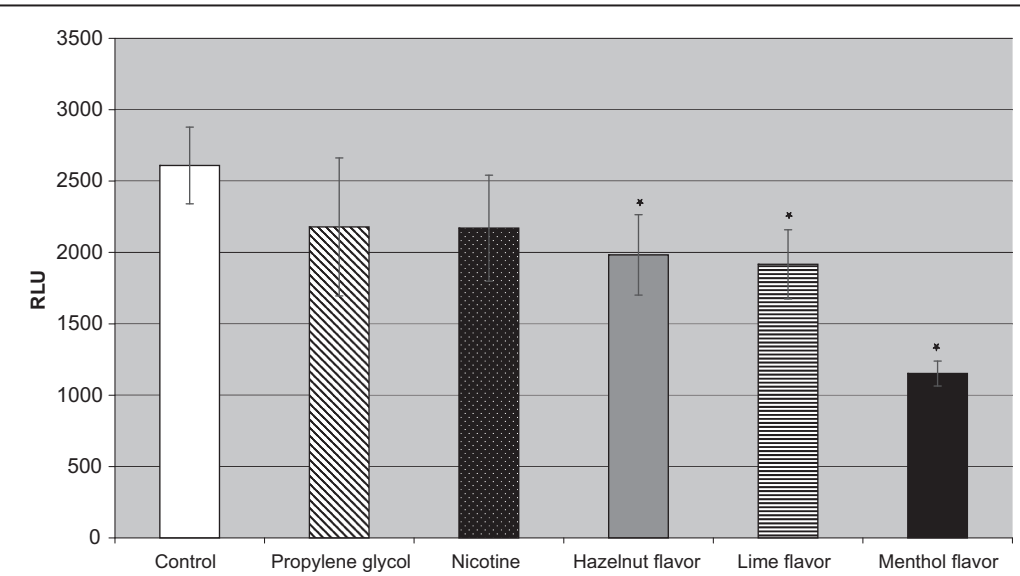

Figure 2 ATP detection in the fibroblasts at an incubation time of $\mathbf{2 4} \mathbf{~ h}$ with the cigarette components and flavors. ${ }^{*} p<0.024$ for cells incubated with hazelnut-flavored liquids versus controls; $p<0.009$ for cells incubated with lime-flavored liquids versus controls; $p<0.001$ for cells incubated with menthol-flavored liquids versus controls. 


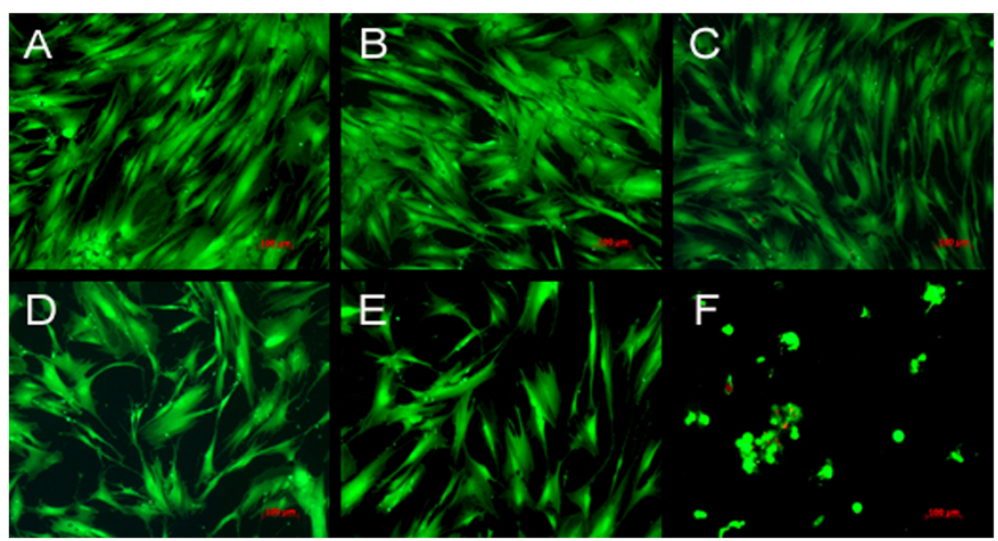

Figure 3 Reaction of the fibroblasts stained with calcein-AM/ethidium homodimer II. Reaction of the periodontal ligament fibroblasts to the different liquids $(\mathbf{A}=$ control; $\mathbf{B}=$ propylene glycol; $\mathbf{C}=$ nicotine; $\mathbf{D}=$ hazelnut flavor, $\mathbf{E}=$ lime flavor, $\mathbf{F}=$ menthol flavor), stained with calcein-AM/ethidium homodimer II after an incubation time of $24 \mathrm{~h}$ (magnification $\times 100$, bar $=100 \mu \mathrm{m}$ ).

\section{Discussion}

In the present study a possible harmful influence of components and different available flavors of e-cigarettes on human fibroblast cells was examined. E-cigarettes have received a great deal of attention and popularity over the past years and they also play an important role in nicotine replacement therapy [29]. E-cigarettes present a valuable alternative for smokers who are willing to quit. Therefore, it is of interest to what extent the main components of the electronic cigarette smoking liquids are potentially harmful. A novelty in e- cigarettes is flavoring as additive and the liquids come in great variety [24].
In our in vitro study it was demonstrated that some additives from e-cigarettes could cause considerable damage to cell proliferation. While some flavorings such as lime or hazelnut did not seem to exert a harmful effect on cell vitality and proliferation, the menthol e-liquid preparation had significant negative impact on periodontal ligament fibroblasts.

In their in vitro study Semlali et al. [30] explored the influence of whole cigarette smoke on the morphology and function of gingival fiboblasts. The authors were able to prove reduced cellular proliferation and vitality, further a reduction of the number of $\beta 1$-integrin-positive cells together with an increased LDH activity [26]. These

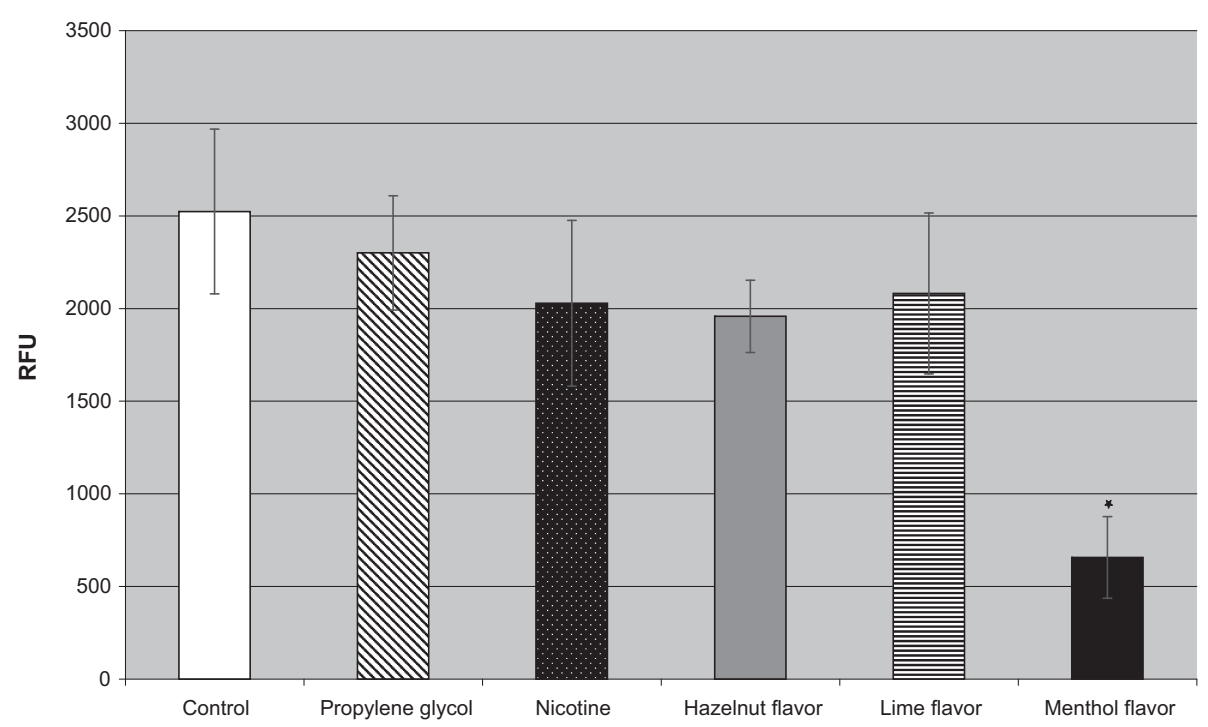

Figure 4 Effect of the different components and flavors of e-cigarettes on the migration rate of fibroblasts at 72 h. ${ }^{*} p<0.001$ versus controls and nicotine-treated cells. 
results demonstrate that even a single exposure to cigarette smoke can produce morphological and functional deregulation in gingival fibroblasts.

The effect of numerous refill solutions of e-cigarettes from an American distributor on human embryonic stem cells and human pulmonary fibroblasts were tested, and it was also shown that various additives such as cinnamon or menthol had a cytotoxic potential [31].

It is known that in particular menthol as a tobacco additive has the effect of masking the bitter taste of cigarette smoke; it was first introduced into cigarettes in 1926 [32].

Conventional and electronic cigarettes often contain menthol. Various effects have been suggested for menthol, such as taste ameliorating, cooling, pain-relieving and a slightly numbing effect; menthol ameliorates the cigarette taste, masks the irritating effect of tobacco smoke and makes the smoke easier to inhale [33]. Furthermore, the potential for addiction is increased through its desensitization ability to nicotine, longer exposure and tolerance to nicotine. Finally the risk of cancer is increased by absorption of tobacco smoke components into the lung [33-36]. Menthol can be contained in several parts of cigarettes, such as in the filter, paper and also in flavored liquids.

Recent studies confirm that the addition of menthol leads to a number of negative effects [37,38]. Furthermore, it was shown that menthol increases the flux of the tobacco-related compounds nitrosamine and nitrosonornicotine across porcine esophagus [39]. It is remarkable that one third of diagnosed esophageal cancers in 1998 was found in females [40] and that about a third of female smokers preferred menthol cigarettes [41].

The harmful effect of additives, in particular with menthol flavor could also be observed and confirmed in our study.

Results from numerous studies providing evidence of a negative influence of menthol additives in cigarettes have lead in 2013 to the decision to ban menthol containing cigarettes in the European Community; in addition, it was proposed to harmonize the regulations of e-cigarettes, which presently differ between the countries in the EU, and to restrict their advertising [42]. Since the present study shows that in particular menthol additives in ecigarettes had a harmful effect on human fibroblast cells, it might be considered to prohibit the use of this additive not only in conventional cigarettes but also in e-cigarettes.

Within its limits, the present in vitro study demonstrated that menthol additives of e-smoking have a harmful effect on human periodontal ligament fibroblasts. This might indicate that it is preferable for e-cigarettes not to contain menthol additives.

\section{Competing interests}

The authors declare that they have no competing interests.
Authors' contributions

IW, TW and BW carried out the study. IW and WW performed the statistical analysis. IW, TW, BW, RS and SG conceived of the study, and participated in its design and coordination. All authors read and approved the final manuscript.

\section{Acknowledgments}

The authors would like to thank Mrs. Claudia Darmstadt for her excellent technical assistance.

\section{Author details}

${ }^{1}$ Department for Operative Dentistry, University Medical Center of the Johannes Gutenberg University Mainz, Augustusplatz 2, 55131 Mainz, Germany. ${ }^{2}$ Institute of Medical Biostatistics, Epidemiology and Informatics (IMBEI), Johannes Gutenberg University Mainz, Mainz, Germany. ${ }^{3}$ Department for Oral, Cranio-Maxillofacial and Facial Plastic Surgery, Medical Center of the Goethe University Frankfurt, Frankfurt am Main, Germany. ${ }^{4}$ Institute of Pathology, REPAIR-Lab, University Medical Center of the Johannes Gutenberg University Mainz, Mainz, Germany.

Received: 13 May 2014 Accepted: 11 September 2014

Published: 15 September 2014

\section{References}

1. Yamin CK, Bitton A, Bates DW: E-Cigarettes: a rapidly growing internet phenomenon. Ann Intern Med 2010, 153(9):607-609.

2. Henningfield JE, Zaatari GS: Electronic nicotine delivery systems: emerging science foundation for policy. Tob Control 2010, 19(2):89-90.

3. Carter CA, Hamm JT: Multiplexed quantitative high content screening reveals that cigarette smoke condensate induces changes in cell structure and function through alterations in cell signaling pathways in human bronchial cells. Toxicology 2009, 261(3):89-102.

4. Chen YT, Gallup M, Nikulina K, Lazarev S, Zlock L, Finkbeiner W, McNamara N: Cigarette smoke induces epidermal growth factor receptor-dependent redistribution of apical MUC1 and junctional beta-catenin in polarized human airway epithelial cells. Am J Pathol 2010, 177(3):1255-1264.

5. Donetti E, Gualerzi A, Bedoni M, Volpari T, Sciarabba M, Tartaglia G, Sforza C: Desmoglein 3 and keratin 10 expressions are reduced by chronic exposure to cigarette smoke in human keratinised oral mucosa explants. Arch Oral Biol 2010, 55(10):815-823

6. Bjartveit $K$, Tverdak A: Health consequences of smoking 1-4 cigarettes per day. Tob Control 2005, 14(5):315-320.

7. Mills AL, Messer K, Gilpin EA, Pierce JP: The effect of smoke-free homes on adult smoking behavior: a review. Nicotine Tob Res 2009, 11(10):1131-1141.

8. Stewart BW, Kleihues P: World Cancer Report. Lyon: WHO International Agency for Research on Cancer 2003, 1-351.

9. Boyle P, Levin B: World Cancer Report. Lyon: WHO International Agency for Research on Cancer 2008, 1-511.

10. Johnson GK, Guthmiller JM: The impact of cigarette smoking on periodontal disease and treatment. Periodontol 2000 2007, 44:178-194.

11. Kibayashi M, Tanaka M, Nishida N, Kuboniwa M, Kataoka K, Nagata H, Nakayama K, Morimoto K, Shizukuishi S: Longitudinal study of the association between smoking as a periodontitis risk and salivary biomarkers related to periodontitis. J Periodontol 2007, 78(5):859-867.

12. Silva D, Cáceres M, Arancibia R, Martínez C, Martínez J, Smith PC: Effects of cigarette smoke and nicotine on cell viability, migration and myofibroblastic differentiation. J Periodont Res 2012, 47(5):599-607.

13. Calsina G, Ramon JM, Echeverria JJ: Effects of smoking on periodontal tissues. J Clin Periodontol 2002, 29(8):771-776.

14. Wan CP, Leung WK, Wong MC, Wong RM, Wan P, Lo EC, Corbet EF: Effects of smoking on healing response to non-surgical periodontal therapy: a multilevel modelling analysis. J Clin Periodontol 2009, 36(3):229-239.

15. Moimaz SA, Zina LG, Saliba O, Garbin CA: Smoking and periodontal disease: clinical evidence for an association. Oral Health Prev Dent 2009, 7(4):369-376.

16. Torrungruang K, Gongsakdi V, Laohaviraphab L, Likittanasombat K, Ratanachaiwong W: Association between cigarette smoking and the intraoral distribution of periodontal disease in Thai men over 50 years of age. $J$ Investig Clin Dent 2012, 3(2):135-141.

17. Chen H, Liu N, Xu X, Qu X, Lu E: Smoking, radiotherapy, diabetes and osteoporosis as risk factors for dental implant failure: a meta-analysis. PLoS One 2013, 8(8):e71955. doi10.1371/journal.phone.0071955. 
18. Underner M, Perriot J, Peiffer G: Le snus. Presse Med 2012, 41(1):3-9.

19. Goniewicz ML, Hajek P, McRobbie H: Nicotine content of electronic cigarettes, its release in vapour and its consistency across batches: regulatory implications. Addiction 2014, 109(3):500-507.

20. Etter JF: Electronic cigarettes. A survey of users. BMC Public Health 2010, 10(4):231.

21. Romagna G, Allifranchini E, Bocchietto E, Todeschi S, Esposito M, Farsalinos KE: Cytotoxicity evaluation of electronic cigarette vapor extract on cultured mammalian fibroblasts (ClearStream-Life): comparison with tobacco cigarette smoke extract. Inhal Toxicol 2013, 25(6):354-461.

22. Kim HJ, Shin HS: Determination of tobacco-specific nitrosamines in replacement liquids of electronic cigarettes by liquid chromatography-tandem mass spectrometry. J Chromatogr A 2013, 1291(24):48-55.

23. Goniewicz ML, Kuma T, Gawron M, Knysak J, Kosmider L: Nicotine levels in electronic cigarettes. Nicotine Tob Res 2012, 15(1):158-166.

24. Chen IL: FDA summary of adverse events on electronic cigarettes. Nicotine Tob Res 2013, 15(2):615-616.

25. Etter JF, Zäther E, Svensson S: Analysis of refill liquids for electronic cigarettes. Addiction 2013, 108(9):1671-1679.

26. Jauch J, Schmalzing D, Schurig V, Emberger R, Hopp R, Köpsel M, Silberzahn W. Werkhoff P: Isolation, synthesis, and absolute configuration of filbertone-the principal flavor component of the hazelnut. Angew Chem Int Ed Engl 1989, 28:1022-1023.

27. Clark BC, Chamblee TS, lacobucci GA: HPLC isolation of the sesquiterpene hydrocarbon germacrene $B$ from lime peel oil and its characterization as an important flavor impact constituent. J Agric Food Chem 1987, 35:514-518.

28. Loizzo MR, Tundis R, Bonesi M, Menichini F, De Luca D, Colica C, Menichini F: Evaluation of Citrus aurantifolia peel and leaves extracts for their chemical composition, antioxidant and anti-cholinesterase activities. J Sci Food Agric 2012, 92:2960-2967.

29. Ayers JW, Ribisl KM, Brownstein JS: Tracking the rise in popularity of electronic nicotine delivery systems (electronic cigarettes) using search query surveillance. Am J Prev Med 2011, 40(4):448-453.

30. Semlali A, Chakir J, Rouabhia M: Effects of whole cigarette smoke on human gingival fibroblast adhesion, growth, and migration. J Toxicol Environ Health A 2011, 74(13):848-862.

31. Bahl V, Lin S, Xu N, Davis B, Wang Y: Comparison of electronic cigarette refill fluid cytotoxicity using embryonic and adult models. Reprod Toxicol 2012, 34(4):529-537.

32. Squier CA, Mantz MJ, Wertz PW: Effect of menthol on the penetration of tobacco carcinogens and nicotine across porcine oral mucosa ex vivo. Nicotine Tob Res 2010, 12(7):763-7.

33. Ahijevych K, Garrett BE: Menthol pharmacology and its potential impact on cigarette smoking behavior. Nicotine Tob Res 2004, 6(1 Suppl);S17-S28.

34. Dessirier JM, O'Mahony M, Carstens E: Oral irritant properties of menthol: sensitizing and desensitizing effects of repeated application and crossdesensitization to nicotine. Physiol Behav 2001, 73(1-2):25-36.

35. Garten S, Falkner RV: Role of mentholated cigarettes in increased nicotine dependence and greater risk of tobacco-attributable disease. Prev Med 2004, 38(6):793-798

36. Kreslake JM, Wayne GF, Connolly GN: The menthol smoker: tobacco industry research on consumer sensory perception of menthol cigarettes and its role in smoking behavior. Nicotine Tob Res 2008, 10(4):705-715.

37. Lu HF, Liu JY, Hsueh SC, Yang YY, Yang JS, Tan TW, Kok LF, Lu CC, Lan SH, Wu SY, Liao SS, Ip SW, Chung JG: Menthol inhibits WEHI-3 leukemia cells in vitro and in vivo. In Vivo 2007, 21(2):285-289.

38. Squier CA, Mantz MJ, Wertz PW: Effect of menthol on the penetration of tobacco carcinogens and nicotine across porcine oral mucosa ex vivo. Nicotine Tob Res 2010, 12(7):763-767.

39. Azzi C, Zhang J, Purdon CH, Chapman JM, Nitcheva D, Hebert JR, Smith EW: Permeation and reservoir formation of 4-(methylnitrosamino)-1-(3-pyridyl)1-butanone (NNK) and benzo [a]pyrene (B [a]P) across porcine esophageal tissue in the presence of ethanol and menthol. Carcinogenesis 2006, 27(1):137-145
40. Brooks-Brunn JA: Esophageal cancer: an overview. Medsurg Nurs 2000, 95(9):248-254.

41. Giovino GA, Sidney S, Gfroerer JC, O'Malley PM, Allen JA, Richter PA, Cummings KM: Epidemiology of menthol cigarette use. Nicotine Tob Res 2004, 6(1 Suppl):S67-S81.

42. European Union: Proposal for a directive of the European Parliament and of the Council on the approximation of the laws, regulations and administrative provisions of the member states concerning the manufacture, presentation and sale of tobacco and related products. 2012, http://www.ec.europa.eu/health/tobacco/docs/com_2012_788_en.pdf.

doi:10.1186/1746-160X-10-39

Cite this article as: Willershausen et al:: Influence of E-smoking liquids on human periodontal ligament fibroblasts. Head \& Face Medicine 2014 10:39.

\section{Submit your next manuscript to BioMed Central and take full advantage of:}

- Convenient online submission

- Thorough peer review

- No space constraints or color figure charges

- Immediate publication on acceptance

- Inclusion in PubMed, CAS, Scopus and Google Scholar

- Research which is freely available for redistribution 